\title{
First Morphological and Molecular Report of Aphelenchoides blastophthorus on Strawberry Plants in Switzerland
}

\author{
Erika Consoli, ${ }^{1}$ Andrea C. Ruthes, ${ }^{2}$ Eder Reinhard, ${ }^{1}$ and Paul Dahlin ${ }^{1, \dagger}$ \\ ${ }^{1}$ Agroscope, Research Division Plant Protection, Phytopathology and Zoology in Fruit and Vegetable Production, Wädenswil, \\ Switzerland \\ ${ }^{2}$ Independent Researcher, Wädenswil, Switzerland
}

\begin{abstract}
Foliar nematodes represent a minor feeding group within the genus Aphelenchoides Fischer, 1894. The facultative plant parasitic species A. blastophthorus can cause crinkling of leaves, reduced vigor, and stunting of agricultural and ornamental plants. Here we report the first finding of $A$. blastophthorus in leaves, crowns, and roots of strawberry plants collected in Switzerland in 2018. Species identification was confirmed by morphological and morphometric characterization supported by molecular

barcoding of 18 S ribosomal RNA (18S), 28S ribosomal RNA (28S), and cytochrome $c$ oxidase I (COI) gene fragment analyses. Phylogenetic analysis of $18 \mathrm{~S}$ indicated that A. blastophthorus was grouped within close distance to A. fragariae, a well-known foliar nematode affecting strawberry plants. Furthermore, the newly generated molecular barcodes of the partial 28S and COI of A. blastophthorus will support species identification in the future.
\end{abstract}

The genus Aphelenchoides is found worldwide and is commonly known to comprise fungal-feeding nematodes (Hunt 1993). Nonetheless, a few Aphelenchoides spp. are known to also feed on leaves, sprouts, or buds of plants (Hunt 1993; Sánchez-Monge et al. 2015). These facultative plant parasitic nematodes can cause severe crinkling of leaves, reduced vigor, and stunting of plants. These so-called foliar, leaf, or bud nematodes are migratory ectoand endoparasites that reproduce sexually (Chanu et al. 2015; Hooper 1975; Hunt 1993). Under optimal conditions, their life cycle takes approximately 2 weeks depending on temperature, humidity, and other environmental factors (Hooper 1975; Hunt 1993). In humid and warm conditions, these nematodes travel in water films on plant surfaces and finally enter leaf tissue, stomata, and plant axes for feeding and reproduction (Jagdale and Grewal 2006; Wallace 1959). Ornamental and agricultural plants are hosts for foliar nematodes such as A. fragariae (Ritzema Bos, 1890) Christie, 1932 (Christie 1932); A. besseyi Christie, 1942 (Christie 1942); A. ritzemabosi (Schwartz, 1911) Steiner \& Buhrer, 1932 (Steiner and Buhrer 1932); A. blastophthorus Franklin, 1952; and a few other species (Hunt 1993; Sánchez-Monge et al. 2015). Early detection of foliar nematodes is challenging because Aphelenchoides spp. can survive in dry plant materials and seeds for numerous years and symptoms can take weeks or months to appear on plants (Browne et al. 2004; Jagdale and Grewal 2006; McCuiston et al. 2007). A. fragariae, A. besseyi, and A. ritzemabosi are found globally, causing severe plant damage on important agronomic crops (Sánchez-Monge et al. 2015). In 1952, Mary T. Franklin reported a disease on Scabiosa caucasica caused by an Aphelenchoides sp. that was described as A. blastophthorus (Franklin 1952). Until now, this species was found in various plant families such as Begoniaceae, Ranunculaceae, Asparagaceae, Rosaceae, Violaceae, and Caprifoliaceae (Sánchez-Monge et al.

${ }^{\dagger}$ Corresponding author: P. Dahlin; paul.dahlin@agroscope.admin.ch

*The $\boldsymbol{e}$-Xtra logo stands for "electronic extra" and indicates that five supplementary figures are published online.

The author(s) declare no conflict of interest.

Accepted for publication 21 May 2019.

(C) 2019 The American Phytopathological Society
2015). Symptoms attributable to the presence of A. blastophthorus in Norwegian strawberries were reported in 1972, 1987, and 2000 but investigations documented a negative effect on strawberry yields and runner production only in 2000 (Haukeland and Brekke 2000; Støen 1987). Although A. blastophthorus is widespread on strawberry, it has not yet been reported in Switzerland. Here, we provide the first report of $A$. blastophthorus isolated from strawberry (Fragaria $\times$ ananassa) in Switzerland.

\section{Materials and Methods}

This study examined Fragaria $\times$ ananassa 'Darselect and Kimberley' in Switzerland.

Nematode isolation and culture. Live specimens were collected from strawberry leaves, crowns, and roots during the early growth season. Cut plant material was placed in water for $12 \mathrm{~h}$, followed by sieving in a $20-\mu \mathrm{m}$ sieve. Specimens were picked under a light microscope for culturing on Botrytis cinerea and for morphological and molecular analysis. Approximately 10 female and 10 male specimens were placed on $B$. cinerea plates, grown on potato dextrose agar medium, and kept in the dark at $20^{\circ} \mathrm{C}$

Fixation and morphological observation. For morphological observations, specimens were heat-killed and directly mounted on temporary slides using water. Permanent slides for higher resolution of particular nematode structures were prepared according to De Grisse (1969). Briefly, heat-relaxed nematodes were treated with a 4\% paraformaldehyde solution and then transferred to anhydrous glycerine. Images were taken with a Zeiss AXIO Imager Z1 optical microscope (Zeiss, Oberkochen, Germany) equipped with a Zeiss AxioCam MRm camera. Final morphometric measurements were recorded using the ZEN Pro program (2012; Zeiss).

Molecular and phylogenetic analysis. DNA was extracted from a single nematode specimen using the modified method of Kawasaki described in Frey and Frey (1995) and Holterman et al. (2012). Partial 18S ribosomal RNA (18S), 28S ribosomal RNA (28S), and cytochrome $c$ oxidase I (COI) gene fragments were obtained by PCR. The first $18 \mathrm{~S}$ fragment was amplified using primers 988F (CTCAAAGATTAAGCCATGC) and 1912R (TTTACGGTCAGAACTAGGG) selected from Holterman et al. (2006). The second 18S fragment was used to extend the sequence downstream, with the modified forward primer $1096 \mathrm{~F}$ (GGTAATTCTGGAGCCAATAC; Holterman et al. 2006) in combination with a newly designed reverse primer Aph3004R (GCATTTACTTGGAATTCCTC). The $28 \mathrm{~S}$ fragment was amplified using the primer combinations 28-81for (TTAAGCATATCATTTAGCGGAGGAA) and 28-1006rev (GTTCGATTAGTCTTTCGCCCCT; 
Holterman et al. 2008). The COI fragment was amplified using the primer pairs COI-F1 (CCTACTATGATTGGTGGTTTTGGTAATTG) and COI-R2 (GTAGCAGCAGTAAAATAAGCACG; Kanzaki and Futai 2002)

The 18S, 28S, and COI PCRs were carried out with the HotStartTaq Master Mix Kit (Qiagen, Hilden, Germany) in the SensoQuest Labcycler (SensoQuest, Göttingen, Germany). The 20- $\mu$ l reaction contained the following: $10 \mu \mathrm{l}$ of HotStarTaq Master Mix plus $0.5 \mu \mathrm{l}$ of each primer (final concentration, $0.4 \mu \mathrm{M}$ ), $1 \mu \mathrm{l}$ of template DNA, and $8 \mu \mathrm{l}$ of molecular-grade water. The PCR program for both $18 \mathrm{~S}$ and $28 \mathrm{~S}$ was first set at $95^{\circ} \mathrm{C}$ for $5 \mathrm{~min}$ for the initial denaturation step, followed by five cycles of $95^{\circ} \mathrm{C}$ for $30 \mathrm{~s}$, annealing at $45^{\circ} \mathrm{C}$ for $30 \mathrm{~s}$, and extension at $72^{\circ} \mathrm{C}$ for $30 \mathrm{~s}$. This first amplification step was followed by 45 cycles of denaturation at $95^{\circ} \mathrm{C}$ for $30 \mathrm{~s}$, annealing at $54^{\circ} \mathrm{C}$ for $30 \mathrm{~s}$, and extension at $72^{\circ} \mathrm{C}$ for $30 \mathrm{~s}$, with a final elongation step at $72^{\circ} \mathrm{C}$ for $5 \mathrm{~min}$ (Holterman et al. 2006). COI was amplified following Kanzaki and Futai (2002). Amplified PCR fragments were purified with the NucleoFast 96 PCR Clean-up Kit (Macherey-Nagel, Düren, Germany) and sequenced using Applied Biosystems Hitachi 3130xl Genetic Analyzers (Applied Biosystems, Foster City, CA).

Original partial sequences of $18 \mathrm{~S}, 28 \mathrm{~S}$, and COI were BLASTed against the NCBI database and aligned with selected published homologous gene sequences of Aphelenchoides spp. using the Geneious R11 program (Kearse et al. 2012).

For phylogenetic analysis, 79 nucleotide sequences of $18 \mathrm{~S}, 32$ sequences of COI, and 50 sequences of $28 \mathrm{~S}$ were aligned using the MAFFT 7 multiple sequence online alignment program (https:// mafft.cbrc.jp/alignment/software/). After alignment, manual curation was done for the 28S sequences, KX356781.1, KX356782.1, and KX356783.1. In addition, the MUSCLE (Molecular Evolutionary Genetic Analysis software version X [MEGA X]) and MCOFFEE (http://tcoffee.crg.cat/apps/tcoffee/index.html) alignment programs were used for verification of the MAFFT alignment shown for the 18S sequences in Supplementary Figures S1, S2, S3, S4, and S5.

Outgroup taxa for phylogenetic analyses were chosen according to previously published data (Holterman et al. 2017; Sánchez-Monge et al. 2017). The best-fit model for $18 \mathrm{~S}, 28 \mathrm{~S}$, and COI phylogenetic analysis was estimated using jModelTest 2.1.10 software (Darriba et al. 2012).

The $18 \mathrm{~S}, 28 \mathrm{~S}$, and COI data sets were empirically analyzed by the maximum likelihood method, using MEGA X (Tamura et al. 2013).

Table 1. Morphometrics of heat-killed females and males of Aphelenchoides blastophthorus Franklin, 1952 extracted from strawberry plants in Switzerland ${ }^{\mathrm{z}}$

\begin{tabular}{lcc}
\hline Characteristic & Females & Males \\
\hline$n$ & 7 & 7 \\
$\mathrm{~L}$ & $710.5 \pm 65.1(545.7-801.6)$ & $660.7 \pm 90.5(540.0-847.0)$ \\
$\mathrm{a}$ & $27.1 \pm 1.3(23.2-28.4)$ & $28.4 \pm 1.1(26.2-29.8)$ \\
$\mathrm{b}$ & $9.9 \pm 0.9(8.7-12.1)$ & $9.0 \pm 0.4(8.0-9.9)$ \\
$\mathrm{c}$ & $14.9 \pm 0.7(13.1-16.1)$ & $15.8 \pm 1.4(13.5-18.1)$ \\
$\mathrm{c}$ & $2.0 \pm 0.1(1.8-24)$ & - \\
Excretory pore & $83.7 \pm 4.7(74.4-89.7)$ & $85.2 \pm 8.6(69.9-101.9)$ \\
Stylet & $12.9 \pm 0.5(11.8-13.8)$ & $14.1 \pm 0.7(12.8-15.3)$ \\
Head width & $6.5 \pm 0.2(6.1-6.9)$ & $6.6 \pm 0.4(5.8-7.3)$ \\
Head height & $3.1 \pm 0.2(2.9-3.5)$ & $2.9 \pm 0.4(2.1-3.5)$ \\
Nerve ring from & $78.8 \pm 4.6(69.3-83.5)$ & $86.0 \pm 7.9(73.0-100.8)$ \\
$\quad$ anterior body & & - \\
Body width at & $24.4 \pm 3.3(18.9-29.3)$ & - \\
$\quad$ vulva level & & - \\
Postuterine sac & $88.6 \pm 16.5(59.9-106.6)$ & $20.6 \pm 1.3(19.0-24.8)$ \\
Spicule length & - & - \\
$\quad$ arc line) & - & $355.1 \pm 33.1(302-397)$ \\
Testis & $68.5 \pm 0.8(66.3-70.0)$ & - \\
V \% &
\end{tabular}

${ }^{\mathrm{z}}$ All measurements are given as the mean $\pm \mathrm{SD}$ (range) in micrometers, except ratios a, b, c, and c' and the percent value $\mathrm{V}$. Note: $\mathrm{n}=$ number of measured specimens; $\mathrm{L}=$ body length; $\mathrm{a}=$ body length/greatest body width; $\mathrm{b}=$ body length/esophagus length from the lips to the esophageal intestinal valve; $c=$ body length/length of tail; c' = tail length / tail diameter at anus or cloaca; V $\%=$ distance of vulva from the lips $\times 100 /$ body length.
The general time reversible $(\mathrm{GTR})+\mathrm{G}+\mathrm{I}$, Kimura 2 parameter $(\mathrm{K} 2)$ $+\mathrm{G}$, and GTR $+\mathrm{G}$ models were respectively chosen for COI, 18S, and $28 \mathrm{~S}$ phylogenetic analysis. Multiple runs were performed for each analysis. Trees were drawn to scale with branch length measures in the number of substitutions. Maximum parsimony analysis was performed for MAFFT alignments using the default settings. For the $18 \mathrm{~S}$ sequences aligned with MAFFT, MUSCLE, and MCOFFEE alignment parameters, the described maximum likelihood criteria and the maximum parsimony phylogenetic algorithm were used.

The partial 18S, 28S, and COI ribosomal DNA sequences of our isolated A. blastophthorus were uploaded to GenBank (accession numbers MK981893, MK981894, and MK981895).

\section{Results}

Taxonomic tree. The taxonomic tree is as follows:

Domain: Eukaryota

Kingdom: Metazoa

Phylum: Nematoda Pott, 1932

Class: Chromadorea Inglis, 1983

Subclass: Chromadoria Pearse, 1942

Order: Rhabditida Chitwood, 1933

Suborder: Tylenchida Thorne, 1949

Infraorder: Tylenchomorpha De Ley and Blaxter, 2002

Superfamily: Aphelenchoidea Fuchs, 1937

Family: Aphelenchoididae Skarbilovich, 1947

Genus: Aphelenchoides Fischer, 1894

Species: Aphelenchoides blastophthorus Franklin, 1952

EPPO codes: APLOBL

Measurements of A. blastophthorus isolated from strawberries are shown in Table 1.

Females. The $\sim 710-\mu \mathrm{m}$-long elongated body is slightly curved on the ventral side when heat relaxed. The lip region is offset and approximately double as wide as high. The cuticle is finely annulated with a lateral field with four incisures stretching about one-seventh of the midbody (Fig. 1; Table 1). The conical tail, ending in a single mucro, is approximately four anal body widths long. The stylet with its distinct basal knobs is $12.9 \pm 0.5 \mu \mathrm{m}$ long (Table 1 ). The pharynx has a strong median bulb with a well-developed valve and a short isthmus surrounded by the nerve ring just anterior to the pharyngointestinal junction and dorsally overlapping pharyngeal glands. The nerve ring is located over one bulb length posterior to the median bulb (approximately four body widths long). The monoprodelphic reproductive system has an outstretched ovary with oocytes arranged in a single row. A postvulval sac extends approximately half-way to two-thirds of the vulva-anus distance. The vulva is located at $\sim 68 \%$ of the total body length.

Males. Males have similar morphological structures as females, aside from reproductive system and caudal region. With a body length of $\sim 660 \mu \mathrm{m}$, males are shorter on average than females, even though the longest measured individual in this study $(847 \mu \mathrm{m})$ was male. Contrary to females, the tail of males is ventrally curled by $90^{\circ}$ or more. Similar to females, the tail carries a simple mucro. The $20.6 \pm 1.3 \mu \mathrm{m}$ spicula are curved ventrally and rose thorn shaped with a moderately developed apex and rostrum. The male posterior end presents three caudal papillae pairs. The first pair is adanal, the second pair is located half-way from the spicula to the tail, and the third papillae pair is located anterior to the mucro.

Molecular diagnostic and phylogenetic analysis. For DNA barcoding, we amplified the target genes $18 \mathrm{~S}, 28 \mathrm{~S}$, and COI. 18S was similar to previous two sequences available in public databases (AY284644.1 and JQ957879.1), both identified as A. blastophthorus. Over our sequenced amplicons covering 1,601 bp, AY284644.1 had a difference of only 6 bp (position: 4, G-A; 5, T-A; 40, C-T; 75, C-T; 629, C-A; and 630, G-A), whereas JQ957879.1 differed in 16 bp (position: 4, G-A; 5, T-A; 40, C-T; 75, C-T; 113, T.A; 585 to 587, A-G; 607, A-G; 611 to 612, T-C; 630, G-A; 965, T-G; 973, T-C; 1,246, T-C; and 1,451, G-A). No matching sequences were retrieved from the NCBI database blasting 


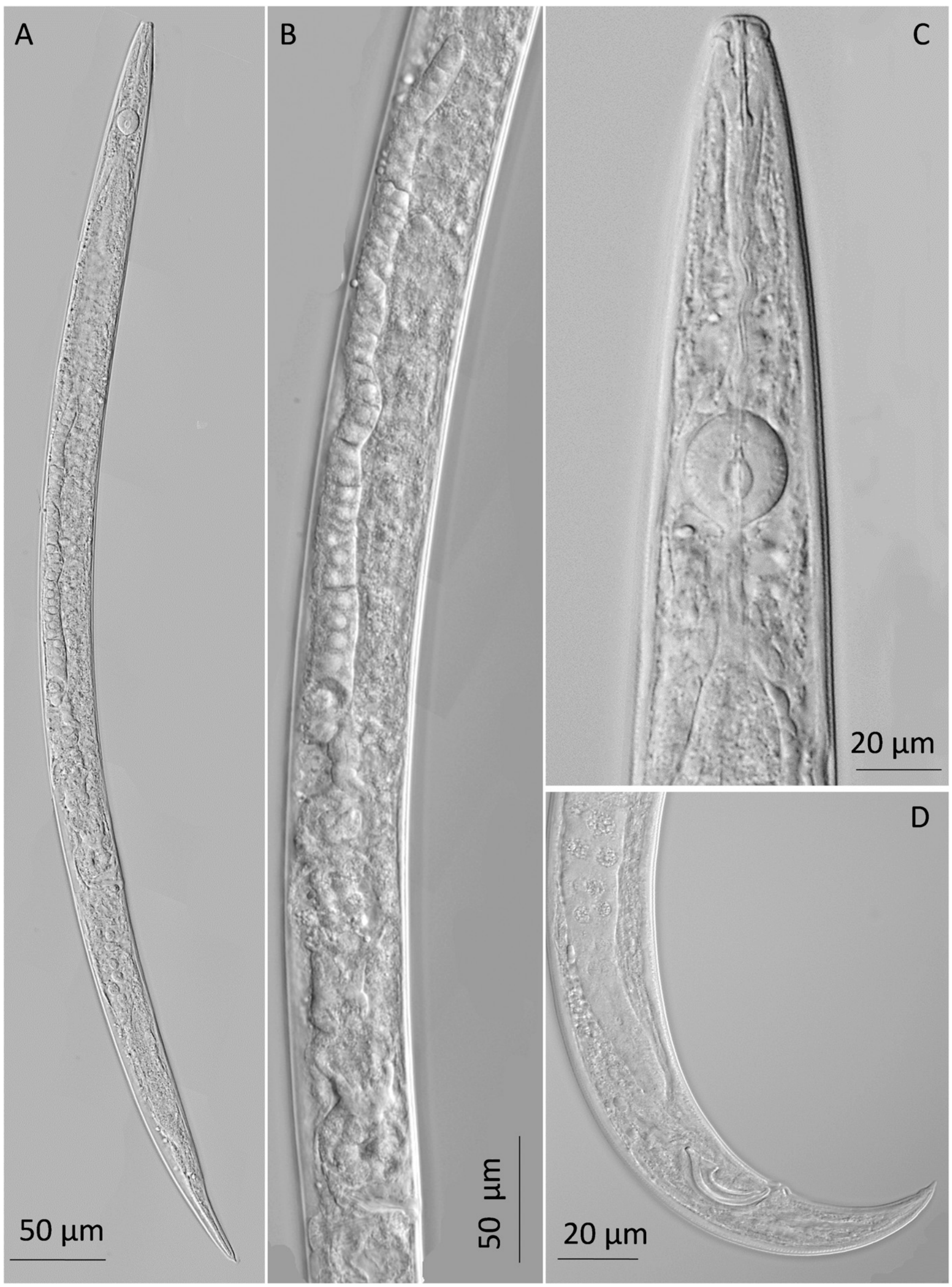

Fig. 1. Aphelenchoides blastophthorus Franklin, 1952. A, Female body, lateral view. B, Female reproductive system. C, Head of male with stylet, pharynx, median bulb, and pharyngeal gland. D, Tail of male with spicula and single mucro. 
our partial $28 \mathrm{~S}$ and COI sequences. We retrieved two COI sequences (393 bp long) from A. blastophthorus from the Q-Bank database, starting at nucleotide $456 \mathrm{bp}$ of our partial COI sequence. The overlap of 190 bp differed in 22 bases (at the following positions: 474, G-T; 492, G-A; 495, G-A; 498, A-T; 499, T-C; 501, A-T; 513, A-T; 519, A-G; 532, T-A; 535, T-C; 537, G-T; 540, G-T; 543, A-G; 582, T-G; 588, G-A; 594, C-T; 603, C-T; 606, C-T; 609, G-T; 615, G-A; $621, \mathrm{~A}-\mathrm{G}$; and $624, \mathrm{C}-\mathrm{T})$. In this way, we enhance diagnostic value of the COI barcode region for diagnostics and phylogenetic analyses.

A maximum likelihood phylogenetic tree with the partial $18 \mathrm{~S}$ and $28 \mathrm{~S}$ rDNA and COI sequences of the group Aphelenchoides was constructed for precise placement of the new sequences. In total, 79, 50, and 32 Aphelenchoides spp. sequences of the 18S, 28S, and COI regions, respectively, were selected, focusing on the four main plant parasitic Aphelenchoides species: A. besseyi, A. fragariae, A. ritzemabosi, and A. subtenuis.

We used the different MAFFT, MUSCLE, and MCOFFEE alignment tools and the maximum likelihood and maximum parsimony tree-building algorithms to evaluate the phylogenetic relationships. It is noteworthy that for all $18 \mathrm{~S}$ rDNA analyses, the plant parasitic Aphelenchoides spp. appeared within two well-supported groups (I and II) (Fig. 2A). All selected methods distinguish unambiguously between group I containing $A$. fujianensis, $A$. ritzemabosi, and $A$. besseyi and group II containing A. blastophthorus, A. fragariae, A. bicaudatus, and $A$. subtenuis, with the lowest support value of a posterior probability $>88 \%$. Our $18 \mathrm{~S}$ rDNA sequence extracted from $A$. blastophthorus was grouped within the A. fragariae, A. bicaudatus, and $A$. subtenuis branch, closely related to the previously described A. blastophthorus sequences (AY284644.1 and JQ957879.1). A. blastophthorus is a neighbor of A. fragariae and then A. saprophilus before branching off to A. clarus, A. bicaudatus, A. varicaudatus, and A. pannocaudus. Of the two $18 \mathrm{~S}$ A. blastophthorus sequences from the databank (i.e., AY284644.1 and JQ957879.1), AY284644.1 grouped closest to our obtained sequence, reflecting the similarity previously described by the base pair differences. A. stammeri and A. composticola are placed well away (Fig. 2A) from the other two Aphelenchoides spp. groups as described previously by Holterman et al. (2017). The 28S rDNA and COI sequences displayed two clusters, although only the $28 \mathrm{~S}$ resolved group II with an informative posterior probability of $84 \%$, but not group I (Fig. 2B and C). According to the COI, the phylogenetic relationship among groups I and II is not supported and remains unresolved. Further phylogenetic analysis of the 28S rDNA and COI sequences showed similar topologies and poor support for the COI phylogenetic relationship and therefore are not shown. The topology obtained from the COI and 28S rDNA sequences followed the main branching structure of the 18S rDNA sequence (Fig. 2).

The two main subclades clearly supported by our $18 \mathrm{~S}$ phylogenetic analysis are in coherence with previously published articles, in which A. blastophthorus, A. fragariae, A. bicaudatus, and A. subtenuis were grouped apart from A. fujianensis, A. ritzemabosi, and A. besseyi (Holterman et al. 2017; Kim et al. 2016; SánchezMonge et al. 2015, 2017).

\section{Discussion}

The genus Aphelenchoides with its mostly slender vermiform habitus is found in diverse environments (Hunt 1993). The first described plant parasitic Aphelenchoides species was A. fragariae (Ritzema Bos 1890), a nematode widespread in Switzerland (CABI 2018a) but not yet reported to cause significant yield losses on strawberry production. Since only the plant parasitic species A. blastophthorus, A. fragariae, and A. ritzemabosi do not present a star-shaped mucro, we can ensure that $A$. besseyi is excluded from entering Switzerland as a potential invasive threat to the country's agriculture (Hunt 1993; Jones at al. 2013). The morphometric parameters and the species characteristics described by Hooper (1975) match well with our studied Aphelenchoides population. In addition to the morphometric parameters, the molecular results of two partial 18S rDNA sequences in the NCBI database (AY284644.1 and JQ957879.1) are consistent with the morphological results, confirming A. blastophthorus as a newly identified species in Swiss agriculture.

Phylogenetic analysis of the partial 18S rDNA sequence for Aphelenchoides spp. branched into two distinct species groups, with branch 1 comprising A. blastophthorus, including the Swiss population described here, A. saprophilus, A. fragariae, A. bicaudatus, A. clarus, and A. subtenuis, and branch 2 containing A. fujianensis, $A$. paradalianensis, A. ritzemabosi, and A. besseyi. Furthermore, these three phylogenetic analyses demonstrate a strong supported clade of A. blastophthorus and A. fragariae by grouping the obtained $18 \mathrm{~S}, 28 \mathrm{~S}$, and COI sequences in close proximity to each other. This is interesting because these nematode species live in similar climate regions, have common host plants, and can live together on the same host (Sánchez-Monge et al. 2015).

Generally, our phylogenetic analysis demonstrates that plant parasitic and fungivorus species are grouped within the same clades, supporting the previous suggestion that plant parasitism arose more than once within the genus (Sánchez-Monge et al. 2017; Fig. 2; A. besseyi and $A$. ritzemabosi in clade 1 , and A. subtenuis, A. fragariae, and $A$. blastophthorus in clade 2).

On a more cautionary note, we cannot exclude whether plant parasitism occurred in a common ancestor of A. blastophthorus, A. fragariae, and the A. subtenuis group and was repeatedly lost over time (e.g., in A. xylocopae, A. bicaudatus, and A. clarus) or if plant parasitism arose independently for A. blastophthorus, A. fragariae, and the $A$. subtenuis group in an earlier event. In the closely related genus Bursaphelenchus, plant parasitic species (e.g., B. xylophilus) are also present and phylogenetically placed among mycophagous species (Sánchez-Monge et al. 2017). The fungal-feeding origin of Aphelenchoides species is consistent with evidence for horizontal gene transfer of the fungal cellulose gene (family GH45), essential for plant parasitism (Haegeman et al. 2011; Palomares-Rius et al. 2014; Sánchez-Monge et al. 2017). The phylogenetic relationships of this cell wall-degrading enzyme support the hypothesis that some Aphelenchoidea acquired these genes from fungi, probably in the context of their fungal-feeding lifestyle, and subsequently marshaled cellulase gene expression in a manner that allowed using it for plant parasitism.

Combining the morphology and phylogenetic analysis, it is remarkable to see that the branching coincides with differences in the morphology of the tail tip in these Aphelenchoides species. A. besseyi, A. fujianensis, and A. ritzemabosi have a star-shaped mucro compared with the single-tipped mucro in A. blastophthorus, A. fragariae, and A. subtenuis or a bifurcate shape for A. bicaudatus (Van Megen et al. 2009). Our 28S and COI analyses support the phylogenetic significance of tail tip shape, grouping A. blastophthorus in the same group with a single terminal mucro.

During the discovery of A. blastophthorus, we also recovered various nonplant parasitic Aphelenchoides spp. from the strawberry plant samples, indicating that a thorough examination for plant parasitic Aphelenchoides spp. should be done if fungal-feeding Aphelenchoides spp. are diagnosed in plant samples.

Although A. blastophthorus is an ecto- and endoparasite on plants, only little is known (or reported) on its effect on global agriculture (Haukeland and Brekke 2000; Sánchez-Monge et al. 2015; Støen 1987). Following the damaging potential on Norwegian strawberries as described in 2000 (Haukeland and Brekke 2000), no newer information about $A$. blastophthorus damaging agricultural plants has been reported to our knowledge. The strawberry plants infested with the A. blastophthorus we detected did not show any characteristic symptoms caused by foliar nematodes.

It is remarkable that plant parasitism of Aphelenchoides spp. is not supported by plant manipulation, preparing a feeding site as reported for other plant parasitic nematodes (Smant et al. 2018). It seems that there is only little systemic interaction between host plants and these facultative plant parasitic nematodes that can cause no damage or minor up to major plant damage, depending on various environmental and unknown factors (CABI 2018b; Haukeland and Brekke 2000; Smant et al. 2018). For example, some plants only show symptoms if highly infested with A. fragariae (International Plant Protection Convention 2016). 
Therefore, even if plants are not symptomatic, planting material should still be checked as a precaution to ensure that it is free of Aphelenchoides spp. (Sánchez-Monge et al. 2015). Generally, preventative measures are key elements in avoiding the introduction or establishment of pathogens within a region. Since A. blastophthorus has been reported from southern to northern Europe (e.g., in Spain, Germany, and Norway; Escuer et al. 2000; Haukeland and Brekke 2000; Sturhan 2014), caution should be taken to avoid further dissemination in Switzerland.

Regarding control of foliar nematodes, nematode-free planting material, sanitation practices, and preplanting treatments with hot water are generally recommended (Goffart 1930; Jagdale and Grewal 2004; Kohl 2011). However, the correct and early detection of the Aphelenchoides species present is essential for rapid implementation of management strategies aiming to contain the spread of the nematode. Since only a few Aphelenchoides species are plant parasitic, multispecies mixtures occur frequently and morphological differentiation between species is difficult, molecular methods are highly valuable tools facilitating rapid and accurate identification.

The link between molecular and morphological identification needs to be more solidly established, as the AY508035.1 sequence shows. AY508035.1 is a partial $18 \mathrm{~S}$ sequence grouped within $A$. fujianensis but identified as A. besseyi. A. besseyi and A. fujianensis can be found together and are difficult to distinguish at the species level, as discussed by Sánchez-Monge et al. (2017). Therefore, it is reasonable to assume that the nematode was misidentified.

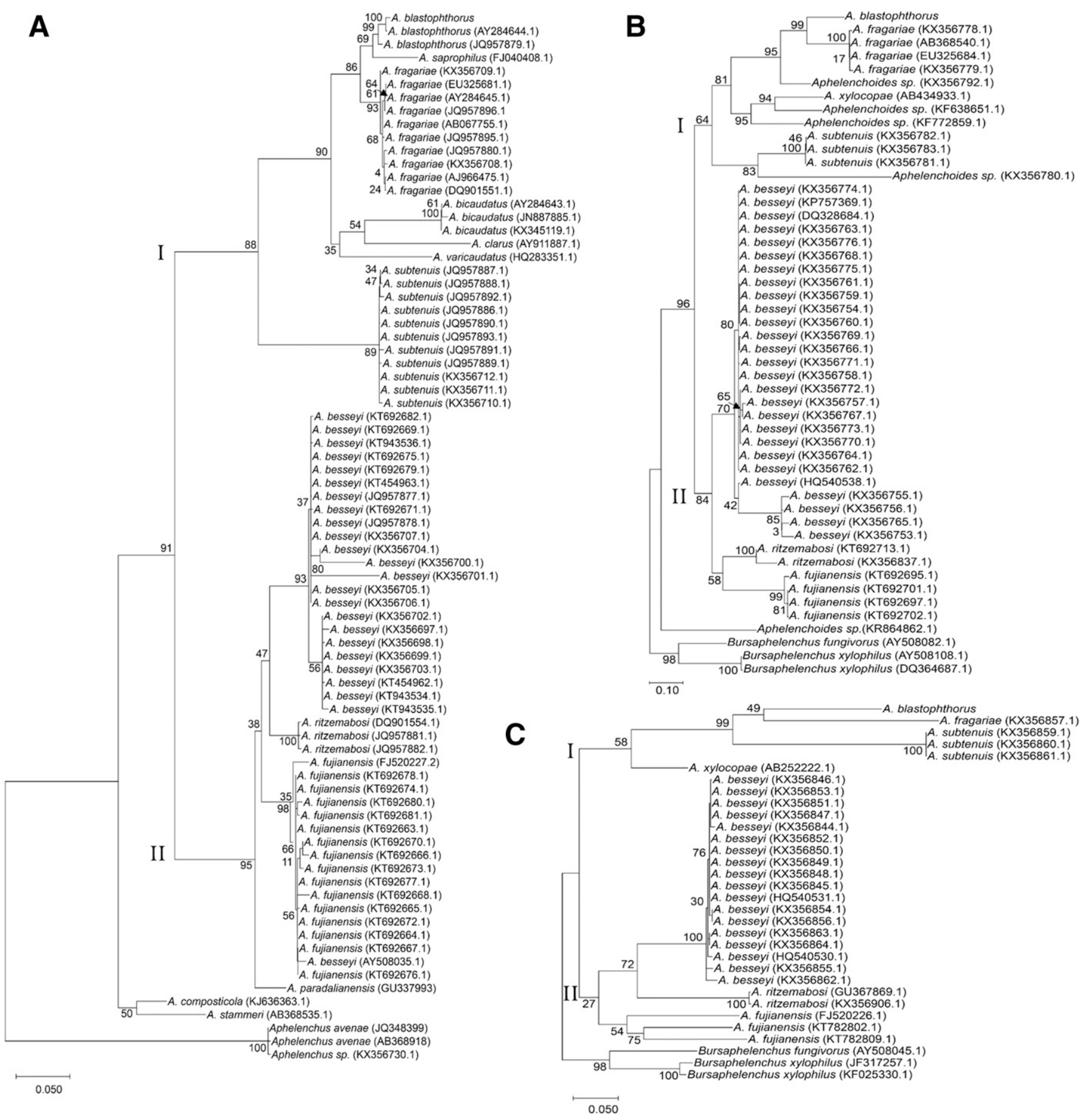

Fig. 2. Phylogenetic tree of Aphelenchoides spp. based on two rRNA markers (18S ribosomal RNA [18S] and 28S ribosomal RNA [28S]) and a mitochondrial marker (cytochrome $C$ oxidase I [COI]). A, Partial 18S sequences. B, Partial 28S sequences. C, Partial COI sequence. The newly obtained $A$. blastophthorus sequences are without the gene identifier in brackets, taken from GenBank. Bayesian inference and the Kimura 2 parameter $(K 2)+G$, general time reversible $(G T R)+G$, and $G T R+G+I$ models were chosen for the $18 S$, $28 \mathrm{~S}$, and $\mathrm{COI}$ phylogenetic analysis, with 500 bootstrap replicates. Branches are proportionally presented and numbers of nodes indicate the posterior probabilities (>95\%). Aphelenchoides spp. are split into two main groups (I and II) indicated above the branch. 
Hence, besides the provided partial $18 \mathrm{~S}$ sequence, the partial $28 \mathrm{~S}$ and COI sequences will further expand the molecular barcoding options available for A. blastophthorus identification. In addition, the morphological characterization in Table 1 and Figure 1 will help to identify A. blastophthorus and support the overall identification.

In conclusion, this work describes the first finding of A. blastophthorus on strawberry plants in Switzerland and provides new molecular sequences for rapid species identification. Although A. blastophthorus is not yet considered a threat for strawberry production, growers should be made aware that this nematode is capable of diminishing strawberry production, and its dissemination should be prevented to avoid potential losses in the future.

\section{Acknowledgments}

Jurg E. Frey and Bea Frey (Agroscope) are acknowledged for sequencing support and supervision in the laboratory. Florian Freimoser (Agroscope) is acknowledged for providing the $B$. cinerea cultures. Johannes Hallmann (Julius Kühn-Institut) and Eduard Holliger (Agroscope) are acknowledged for proofreading the manuscript and helpful suggestions.

\section{Literature Cited}

Browne, J. A., Dolan, K. M., Tyson, T., Goyal, K., Tunnacliffe, A., and Burnell, A. M. 2004. Dehydration-specific induction of hydrophilic protein genes in the anhydrobiotic nematode Aphelenchus avenae. Eukaryot. Cell 3:966-975.

CABI. 2018a. Aphelenchoides fragariae (strawberry crimp nematode). In: Invasive Species Compendium. CAB International, Wallingford, UK. https:// www.cabi.org/isc

CABI. 2018b. Aphelenchoides arachidis (groundnut testa nematode). In: Invasive Species Compendium. CAB International, Wallingford, UK. https://www.cabi.org/isc

Chanu, L. B., Mohilal, N., Victoria, L., and Shah, M. M. 2015. Eight known species of Aphelenchoides nematodes with description of a new species from Manipur, India. J. Parasit. Dis. 39:225-233.

Christie, J. R. 1932. Recent observations on the strawberry dwarf nematode in Massachusetts. Plant Dis. Rep. 16:113-114

Christie, J. R. 1942. A description of Aphelenchoides besseyi n. sp., the summerdwarf nematode on strawberries, with comments on the identity of Aphelenchoides subtenuis (Cobb, 1926) and Aphelenchoides hodsoni Goodey, 1935. Proc. Helminthol. Soc. Wash. 9:82-84.

Darriba, D., Taboada, G. L., Doallo, R., and Posada, D. 2012. jModelTest 2: More models, new heuristics and parallel computing. Nat. Methods 9:772.

De Grisse, A. T. 1969. Redescription ou modification de quelques techniques utilisées dans l'étude des nematodes phytoparasitaires. Meded. Rijksuniversiteitfakulteit Landbouwwet. Gent 34:351-369.

Escuer, M., Arias, M., and Bello, A. 2000. Aphelenchoidoidea nematodes of phytopathological interest and their distribution in Spain. (Abstract). Nematology 2:754.

Franklin, M. T. 1952. A disease of Scabiosa caucasica caused by the nematode Aphelenchoides blastophthorus n. sp. Ann. Appl. Biol. 39:54-60.

Frey, J. E., and Frey, B. 1995. Molecular identification of six species of scale insects (Quadraspidiotus sp.) by RAPD-PCR: Assessing the field-specificity of pheromone traps. Mol. Ecol. 4:777-780.

Goffart, H. 1930. Die Aphelenchen der Kulturpflanzen. Monographien zum Pflanzenschutz. Springer, Berlin, Germany.

Haegeman, A., Jones, J. T., and Danchin, E. G. 2011. Horizontal gene transfer in nematodes: A catalyst for plant parasitism? Mol. Plant-Microbe Interact. 24: 879-887.

Haukeland, S., and Brekke, K. 2000. Yield loss in strawberries caused by Aphelenchoides blastophthorus. (Abstract). Nematology 2:759.

Holterman, M., Karegar, A., Mooijman, P., van Megen, H., van den Elsen, S., Vervoort, M. T., Quist, C. W., Karssen, G., Decraemer, W., Opperman, C. H., Bird, D. M., Kammenga, J., Goverse, A., Smant, G., and Helder, J. 2017. Disparate gain and loss of parasitic abilities among nematode lineages. PLoS One 12:e185445.

Holterman, M., Rybarczyk, K., Van den Elsen, S., Van Megen, H., Mooyman, P., Santiago, R. P., Bongers, T., Bakker, J., and Helder, J. 2008. A ribosomal DNA-based framework for the detection and quantification of stress-sensitive nematode families in terrestrial habitats. Mol. Ecol. Resour. 8:23-34

Holterman, M., van der Wurff, A., van den Elsen, S., van Megen, H., Bongers, T., Holovachov, O., Bakker, J., and Helder, J. 2006. Phylum-wide analysis of SSU rDNA reveals deep phylogenetic relationships among nematodes and accelerated evolution toward crown clades. Mol. Biol. Evol. 23:1792-1800.
Holterman, M. H., Oggenfuss, M., Frey, J. E., and Kiewnick, S. 2012. Evaluation of high-resolution melting curve analysis as a new tool for root-knot nematode diagnostics. J. Phytopathol. 160:59-66.

Hooper, D. J. 1975. Aphelenchoides blastophthorus in C.I.H. Descriptions of Plant-Parasitic Nematodes Set 5, No. 73. CAB International, Wallingford, UK; and Commonwealth Institute of Helminthology, St Albans, UK.

Hunt, D. J. 1993. Aphelenchida, Longidoridae and Trichodoridae: Their Systematics and Bionomics. CAB International, Wallingford, UK.

International Plant Protection Convention. 2016. ISPM 27: Diagnostic Protocols for Regulated Pests. DP 17: Aphelenchoides besseyi, A. fragariae and A. ritzemabosi. International Plant Protection Convention, Rome, Italy.

Jagdale, G. B., and Grewal, P. S. 2004. Effectiveness of a hot water drench for the control of foliar nematodes Aphelenchoides fragariae in floriculture. J. Nematol. 36:49-53.

Jagdale, G. B., and Grewal, P. S. 2006. Infection behavior and overwintering survival of foliar nematodes, Aphelenchoides fragariae, on hosta. J. Nematol. 38:130-136.

Jones, J., Haegeman, A., Danchin, E., Gaur, H., Helder, J., Jones, M., Kikuchi, T., Manzanilla-Lopez, R., Palomares-Rius, J., Wesemael, W., and Perry, R. 2013. Top 10 plant-parasitic nematodes in molecular plant pathology. Mol. Plant Pathol. 14:946-961

Kanzaki, N., and Futai, K. 2002. A PCR primer set for determination of phylogenetic relationships of Bursaphelenchus species within the xylophilus group. Nematology 4:35-41.

Kearse, M., Moir, R., Wilson, A., Stones-Havas, S., Cheung, M., Sturrock, S. Buxton, S., Cooper, A., Markowitz, S., Duran, C., Thierer, T., Ashton, B. Mentjies, P., and Drummond, A. 2012. Geneious Basic: An integrated and extendable desktop software platform for the organization and analysis of sequence data. Bioinformatics 28:1647-1649.

Kim, J., Kim, T., and Park, J. K. 2016. First report of Aphelenchoides bicaudatus (Nematoda: Aphelenchoididae) from South Korea. Anim. Syst. Evol. Divers. 32:253.

Kohl, L. M. 2011. Foliar nematodes: A summary of biology and control with a compilation of host range. Plant Health Prog. 12:23.

McCuiston, J. L., Hudson, L. C., Subbotin, S. A., Davis, E. L., and Warfield, C. Y. 2007. Conventional and PCR detection of Aphelenchoides fragariae in diverse ornamental host plant species. J. Nematol. 39:343-355.

Palomares-Rius, J. E., Hirooka, Y., Tsai, I. J., Masuya, H., Hino, A., Kanzaki, N., Jones, J. T., and Kikuchi, T. 2014. Distribution and evolution of glycoside hydrolase family 45 cellulases in nematodes and fungi. BMC Evol. Biol. 14:69.

Ritzema Bos, J. 1890. De bloemkoolziekte der aardbeien, veroorzaakt door Aphelenchus fragariae nov. spec. (Voorloopige mededeeling). Maanblad Natuurwetensch 16:107-117.

Sánchez-Monge, A., Janssen, T., Fang, Y., Couvreur, M., Karssen, G., and Bert, W. 2017. mtCOI successfully diagnoses the four main plant-parasitic Aphelenchoides species (Nematoda: Aphelenchoididae) and supports a multiple origin of plant-parasitism in this paraphyletic genus. Eur. J. Plant Pathol. 148:853-866.

Sánchez-Monge, G. A., Flores, L., Salazar, L., Hocland, S., and Bert, W. 2015. An updated list of the plants associated with plant-parasitic Aphelenchoides (Nematoda: Aphelenchoididae) and its implications for plant-parasitism within this genus. Zootaxa 4013:207-224

Schwartz, M. 1911. Die Aphelenchen der Veilchengallen und Blattflecken an Farnen und Chrusanthemum. Arb. Ksl. Biol. Anst. Land- u. Forstw. 8:303-334.

Smant, G., Helder, J., and Goverse, A. 2018. Parallel adaptations and common host cell responses enabling feeding of obligate and facultative plant parasitic nematodes. Plant J. 93:686-702.

Steiner, G., and Buhrer, E. M. 1932. Miscellaneous notes on nemic diseases. Plant Dis. Rep. 16:137.

Støen M. 1987. Bladnematoden Aphelenchoides blastophthorus, nytt skadedyr på jordbær. Plakat utstilling: Informasjonsmøte i plantevern, Ås, 1987.

Sturhan, D. 2014. Plant-parasitic nematodes in Germany-an annotated checklist. Soil Org. 86:177-198.

Tamura, K., Stecher, G., Peterson, D., Filipski, A., and Kumar, S. 2013. MEGA6: molecular evolutionary genetics analysis version 6.0. Mol. Biol. Evol. 30: $2725-2729$

Van Megen, H., Elsen, S., Holterman, M., Karssen, G., Mooyman, P., Bongers, T., Holovachov, O., Bakker, J., and Helder, J. 2009. A phylogenetic tree of nematodes based on about 1200 full-length small subunit ribosomal DNA sequences. Nematology 11:927-950.

Wallace, H. R. 1959. Movement of eelworms. V. Observation on Aphelenchoides ritzemabosi (Schwartz, 1912) Steiner, 1932, on florists' chrysanthemums. Ann. Appl. Biol. 47:350-360 